\title{
Minilaparotomy for malfunctioning peritoneal dialysis catheter by nephrologists: experiences at two centers
}

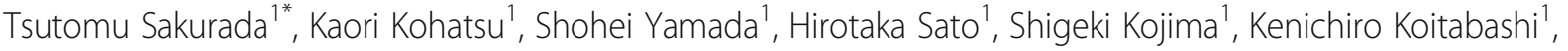 \\ Nagayuki Kaneshiro ${ }^{2}$ and Yugo Shibagaki ${ }^{1}$
}

\begin{abstract}
Catheter malfunction is one of the most important complications of peritoneal dialysis (PD). We have performed minilaparotomy for catheter repair by nephrologists. This study aimed to evaluate the effectiveness and safety of the surgery. The surgery was performed 11 times on 10 PD patients with catheter malfunction ( 3 man, 7 women; mean age $54.3 \pm 14.6$ years; 4 diabetes, 3 glomerulonephritis, 3 other) at two hospitals. All patients had inflow and/ or outflow obstruction. One patient had inserted the PD catheter using conventional surgical technique, and the remaining nine patients had used Moncrief-Popovich technique. Seven patients with catheters embedded using the Moncrief-Popovich technique showed catheter occlusion at the time of externalization. The remaining three patients experienced catheter obstruction $6.0 \pm 2.9$ months after commencing PD. The cause of obstruction was fibrin in six patients, wrapping by fimbriae of the fallopian tube in two patients, omentum wrapping in two patients. One patient had no blockage in the catheter. Operative time was $97 \pm 46 \mathrm{~min}$, and no intraoperative complications were observed. PD was interrupted for $5.9 \pm 3.0$ days and was resumed without leakage in all patients. However, catheter malfunction recurred in one patient 3 months after the surgery. The mean hospital stay was $22.4 \pm 14.7$ days. Minilaparotomy by nephrologists is a safety and suitable for the management of catheter malfunction. In addition, it is necessary to always consider the possibility that the catheter has been occluded at the time of externalization in the Moncrief-Popovich technique.
\end{abstract}

Keywords: Peritoneal dialysis, Catheter malfunction, Catheter repair, Minilaparotomy

\section{Introduction}

The most frequent complications in peritoneal dialysis (PD) are catheter-related infections, but catheter malfunction is well-known as a relatively frequent complication. The cause of catheter malfunction is obstruction of the catheter or catheter tip migration in the abdominal cavity. Obstruction can result from intraluminal catheter occlusion (fibrin, blood clot) or extraluminal catheter occlusion (wrapping by omentum or fimbriae of the

\footnotetext{
* Correspondence: sakurada@marianna-u.ac.jp

'Division of Nephrology and Hypertension, Department of Internal Medicine, St. Marianna University School of Medicine, Kawasaki, Japan

Full list of author information is available at the end of the article
}

fallopian tube). Non-invasive catheter flushing of the obstruction is usually attempted first, but often fails.

When PD became widespread in the 1980s, catheter removal or replacement was common as a surgical treatment for catheter obstruction [1]. In the 1990s, laparoscopy was applied to various surgeries, and laparoscopic surgery for catheter obstruction has also been performed [2-4]. In general, laparoscopic surgery shows many advantages for patients compared with laparotomy (Table 1). On the other hand, one of the most important disadvantages of laparoscopic surgery is that expensive medical equipment is required to perform surgery. In addition, surgery requires special skills, and not all surgeons can

C C The Author(s). 2020 Open Access This article is licensed under a Creative Commons Attribution 4.0 International License, which permits use, sharing, adaptation, distribution and reproduction in any medium or format, as long as you give appropriate credit to the original author(s) and the source, provide a link to the Creative Commons licence, and indicate if changes were made. The images or other third party material in this article are included in the article's Creative Commons licence, unless indicated otherwise in a credit line to the material. If material is not included in the article's Creative Commons licence and your intended use is not permitted by statutory regulation or exceeds the permitted use, you will need to obtain permission directly from the copyright holder. To view a copy of this licence, visit http://creativecommons.org/licenses/by/4.0/ The Creative Commons Public Domain Dedication waiver (http://creativecommons.org/publicdomain/zero/1.0/) applies to the data made available in this article, unless otherwise stated in a credit line to the data. 
Table 1 Comparison between laparoscopic surgery and laparotomy

\begin{tabular}{lll}
\hline & $\begin{array}{l}\text { Laparoscopic } \\
\text { surgery }\end{array}$ & Laparotomy \\
\hline Length of skin incision & Small & Large \\
Operation time & Long & Short \\
Postoperative pain & Mild & Severe \\
Postoperative recovery & Quick & Slow \\
Risk of incisional hernia & Low & High \\
Risk of surgical site infection & Low & High \\
Length of hospitalization & Short & Long \\
Laparoscopic skills & Necessary & Unnecessary \\
Observation in the abdominal & Possible & Impossible \\
cavity & & \\
Laparoscopic equipment & Necessary & Unnecessary \\
Medical cost & High & Low \\
Anesthesia & General & General or \\
& & local \\
\hline
\end{tabular}

use a laparoscope. Indeed, it has also been reported that the incidence of complications due to laparoscopic surgery is related to the experience of the surgeon [5]. Furthermore, laparotomy can be performed under local anesthesia, but most laparoscopic surgeries require general anesthesia.

In 2008, Kim et al reported minilaparotomy under local anesthesia for catheter malfunction by surgeons for the first time [6]. Li et al, a Taiwanese urologists, also performed a small laparotomy for catheter malfunction and performed simultaneous catheter abdominal wall fixation, demonstrating its usefulness [7]. A number of nephrologists in Japan have reportedly been performing surgeries related to peritoneal access [8]. Therefore, many nephrologists also have performed this procedure for catheter malfunction, but all of which are only case reports. We believe that this procedure can be performed by a nephrologist, and we have performed it on 11 patients. The retrospective observational study aimed to evaluate the effectiveness and safety of minilaparotomy by nephrologists.

\section{Methods}

Between April 2011 and November 2019, a total of 185 PD catheter placements were performed at St. Marianna University School of Medicine Hospital and Kawasaki Municipal Tama Hospital. Of these, 138 catheters were embedded using the Moncrief-Popovich technique [9], and 127 catheters had been externalized as of November 2019. The remaining 47 catheters were placed using conventional surgical techniques with creation of an exit site. We retrospectively evaluated the patients who performed minilaparotomy for catheter malfunction and investigated the background characteristics (age, sex, primary disease of end-stage kidney disease, body mass index, past history of abdominal surgery), cause of obstruction, type of catheter, type of anesthesia, operative time, intraoperative complications, PD interruption period, hospital stay, and postoperative outcomes. Laparotomy was selected for these surgeries (catheter placements and catheter repairs) because nephrologists are not allowed to use laparoscopy in PD catheter-related surgeries at our facilities. The study was approved by the institutional review boards of the two hospitals (No. 4302).

\section{Minilaparotomy for catheter repair}

First, a bag containing dialysate was connected to the patient's connecting tube before surgery. The reason for this connection is to confirm intraoperatively whether dialysate can be smoothly infused after apparent release of the obstruction. Intravenous cefazolin (1 g) was administered as antibiotic prophylaxis just prior to surgery. A skin incision of about $4 \mathrm{~cm}$ was made on the caudal side from the catheter insertion wound, fat tissue was detached, the anterior rectus sheath was dissected, rectus muscle was bluntly divided, and the peritoneum was reached. The peritoneum was incised to a length of approximately $1.5 \mathrm{~cm}$, and the abdominal cavity was identified. The forefinger was then inserted into the abdominal cavity, and the catheter was slowly removed. As a key point in removal, the catheter is easy to take out by rolling the catheter with fingertip. If the catheter could be removed without resistance, we examined the cause of the obstruction. After removing the obstruction from the catheter, dialysate was injected to confirm catheter function. Finally, the catheter was manually inserted into the peritoneal cavity, the peritoneum was closed tightly with continuous suturing, and the anterior rectus sheath and skin were sutured.

\section{Results}

Table 2 shows details for the 10 patients who performed minilaparotomy for catheter malfunction (3 man, 7 women; mean age $54.3 \pm 14.6$ years). In case 8 , catheter malfunction was recurred 3 months after the minilaparotomy, and the second minilaparotomy was performed. The underlying pathology was unknown in 1 case, nephrosclerosis in 1 case, polycystic kidney in 1 case, diabetes in 4 cases, and glomerulonephritis in 3 cases. The mean body mass index at the time of minilaparotomy was $22.6 \pm 3.6 \mathrm{~kg} / \mathrm{m}^{2}$. Three of the 11 patients had a history of abdominal surgery, comprising ectopic pregnancy in one, kidney transplantation in one, and ovarian cystectomy in the other. One patient had inserted the PD catheter using conventional surgical technique, and the remaining nine patients had used Moncrief-Popovich 
Table 2 Background of peritoneal dialysis patients who underwent minilaparotomy

\begin{tabular}{lllllll}
\hline Case & Age (years) & Sex & Primary disease of ESKD & BMl $\left(\mathrm{kg} / \mathrm{m}^{2}\right)$ & Past history of abdominal surgery & Moncrief-Popovich technique \\
\hline 1 & 54 & Male & PKD & 24.9 & None & Yes \\
2 & 65 & Female & Unknown & 24.5 & None & Yes \\
3 & 67 & Female & CGN & 24.2 & Ectopic pregnancy & Yes \\
4 & 73 & Female & CGN & 19.8 & None & No \\
5 & 84 & Female & DKD & 22.8 & None & Yes \\
6 & 83 & Female & Nephrosclerosis & 20.7 & None & Yes \\
7 & 59 & Female & DKD & 30.4 & Ovarian cystectomy & Yes \\
8 & 34 & Female & MPGN & 19.7 & Kidney transplantation & Yes \\
9 & 58 & Male & DKD & 21.4 & None & Yes \\
10 & 66 & Male & DKD & 18.0 & None &
\end{tabular}

ESKD End-stage kidney disease, BMI Body mass index, eGFR Estimated glomerular filtration rate, PKD Polycystic kidney disease, CGN Chronic glomerulonephritis, $D K D$ Diabetic kidney disease, MPGN Membranoproliferative glomerulonephritis

technique. Three types of catheter were placed as follows: Swan Neck Sendai Catheter with $0.7 \mathrm{~mm}$ lateral hole and $2.6 \mathrm{~mm}$ tip hole (JB-5(A); Hayashidera, Ishikawa, Japan) in 1 patient, Straight Long Shoot Catheter with $0.7 \mathrm{~mm}$ lateral hole and $2.6 \mathrm{~mm}$ tip hole (JL-3(A)S3; Hayashidera) in 5 patients, and JBS-2 slit-type semi-long catheters with 0.5 $\mathrm{mm}$ lateral hole and $2.0 \mathrm{~mm}$ tip hole (Meditech, Tokyo, Japan) in 4 patients. All patients had inflow and/or outflow obstructions. Table 3 shows postoperative outcomes of minilaparotomy. Minilaparotomy was performed under local anesthesia in 1 patient, spinal anesthesia in 2 patients, and general anesthesia in 7 patients. Among the 10 patients, 7 catheters had been occluded at externalization. In those cases, the mean burial period was $10.3 \pm 5.1$ months, and most of the cause of obstructions was fibrin. The remaining 3 patients experienced catheter obstruction $6.0 \pm 2.9$ months after commencing PD; the cause of obstruction was wrapping by fimbriae of the fallopian tube in two patients and omentum wrapping in two patients. One patient had no blockage in the catheter. Omentectomy was added for two patients with omentum wrapping. Figure 1 shows a catheter wrapped by fimbriae of the fallopian tube. The mean operative time for minilaparotomy was $97 \pm 46 \mathrm{~min}$, and no intraoperative complications were observed. PD interruption period was $5.9 \pm 3.0$ days, and PD could be resumed without leakage in all patients. The mean hospital stay was $22.4 \pm 14.7$ days, and PD was able to be resumed without trouble after discharge.

\section{Discussion}

A recent study reported the incidence of catheter malfunction due to obstruction as within the range of 3$20 \%$ [10]. In our study, 10 patients experienced catheter obstruction among 174 patients who initiated PD. The incidence of catheter malfunction was thus approximately $6.0 \%$, but this result included cases used the Moncrief-

Table 3 Postoperative outcomes of minilaparotomy

\begin{tabular}{|c|c|c|c|c|c|}
\hline Case & Cause of obstruction & $\begin{array}{l}\text { Malfunction onset time or [burial period] } \\
\text { (months) }\end{array}$ & $\begin{array}{l}\text { Operative time } \\
\text { (min) }\end{array}$ & $\begin{array}{l}\text { Interruption period } \\
\text { (days) }\end{array}$ & $\begin{array}{l}\text { Hospital stay } \\
\text { (days) }\end{array}$ \\
\hline 1 & Fibrin & [11] & 47 & 7 & 10 \\
\hline 2 & Fibrin & [19] & 60 & 6 & 6 \\
\hline 3 & Fibrin & [9] & 48 & 3 & 6 \\
\hline 4 & $\begin{array}{l}\text { Fimbriae of fallopian } \\
\text { tube }\end{array}$ & 9 & 59 & 4 & 14 \\
\hline 5 & Fibrin & [8] & 87 & 7 & 29 \\
\hline 6 & Fibrin & {$[12]$} & 87 & 5 & 43 \\
\hline 7 & Fibrin & [11] & 83 & 14 & 32 \\
\hline 8 & $\begin{array}{l}\text { Fimbriae of fallopian } \\
\text { tube }\end{array}$ & {$[2]$} & 187 & 6 & 49 \\
\hline 8 & Omentum & 3 & 124 & 5 & 23 \\
\hline 9 & Omentum & 4 & 132 & 4 & 11 \\
\hline 10 & NONE & 8 & 150 & 4 & 23 \\
\hline
\end{tabular}




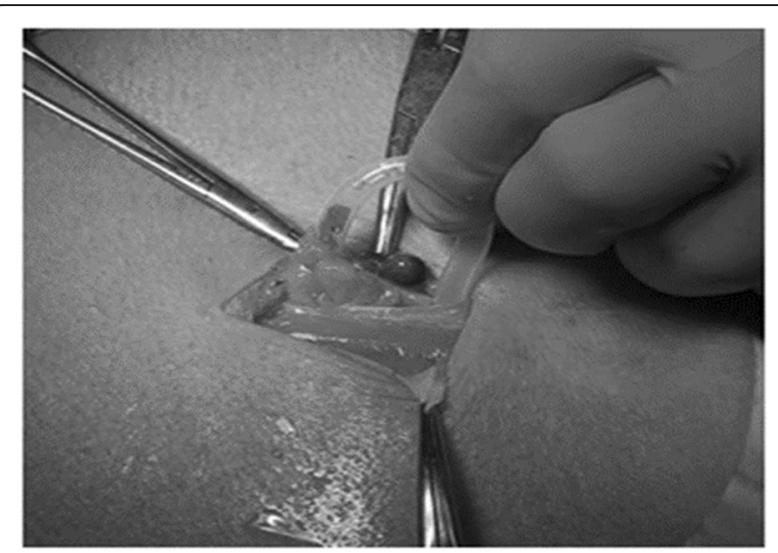

Fig. 1 Fimbriae of the fallopian tube are wrapped around the side hole and tip of the catheter, which is taken out with the nephrologist's forefinger. In addition, the lumen of the catheter contains necrotic tissue

Popovich technique. The incidences of catheter malfunctions in previous studies only have been reported for the conventional surgical technique. In our study, covering a period of about 8 years, only four patients $(2.3 \%)$ had catheter malfunction during PD. The incidence rate, calculated over the observation period of 587 patient-years, was 0.019 episodes per patient-year. The incidence rate in conventional surgical technique group was 0.0017 patientyears, whereas that in Moncrief-Popovich technique group was 0.017 patient-years. We therefore believe that the incidence of catheter obstruction for the conventional surgical technique has been low at our facilities.

Several reports have examined the relationship between the duration of embedment and catheter malfunction in the Moncrief-Popovich technique. Brown et al. reported catheter malfunction in $6 \%$ of patients treated using Moncrief-Popovich technique, and the incidence of primary catheter failure was high among patients with late externalization [11]. In addition, Crabtree et al. reported catheter malfunction in 14.3\% of 84 catheters with mean embedment duration of 13.9 months [12]. According to a recent study, increasing embedment duration was a significant predictor of catheter non-function at the time of externalization [13]. In our study, $5.1 \%$ of patients (7 out of 138 catheters) treated using the MoncriefPopovich technique showed catheter obstruction. Most patients had embedment duration of more than 8 months. These results suggest that the conventional surgical technique may be better than the MoncriefPopovich technique in patients who may be buried for more than 8 months.

Catheter occlusion caused by fimbriae of the fallopian tube is relatively rare, although some case reports have been published since the 1980s [14, 15]. In past reports, wrapping by fimbriae of the fallopian tube was most often found in young female patients, in which case issues of fertility had to be considered. In case 4 , fimbriae of the fallopian tube removed because the patient was elderly, while case 8 was preserved because she was young. In addition, catheter obstruction due to fimbriae of the fallopian tube is reportedly often associated with lower abdominal pain, but two patients were asymptomatic except for catheter malfunction. One patient had no blockage in the catheter at minilaparotomy. It is possible that the wrapping by omentum was released during the minilaparotomy, or that the tip of catheter had entered in-between intestinal tracts.

As mentioned in the introduction, minilaparotomy has been reported by surgeons, with a minimum of $28 \mathrm{~min}$ and a maximum of $51 \mathrm{~min}[6,7]$. In contrast, nephrologists had significantly longer operative times, with additional operations such as omental resection taking more than $2 \mathrm{~h}$. However, there was no complication due to anesthesia, and resumption of PD without leakage was possible.

Although we have already mentioned the general advantages of laparoscopic surgery, various advantages unique to catheter repair are also present. First, the cause of catheter malfunction can be clarified under direct vision. With fluoroscopic images using contrast agent, although catheter kinking or the location of the catheter obstruction can be confirmed, identifying the specific cause of the obstruction is not possible. Second, a noteworthy advantage of laparoscopic surgery is the ability to treat occlusion and prevent relapse at the same time as reaching the diagnosis. Preventive surgeries for catheter malfunction include omentectomy, omentopexy, and laparoscopic internal fixation [16-18]. Although such preventive surgeries are reportedly effective for preventing catheter malfunction, most of the studies in this area have been case accumulation studies, with few randomized controlled trials.

A disadvantage of laparoscopic surgery for catheter repair is leakage from the insertion port. PD interruption of at least 2-3 weeks after surgery is required to avoid leakage. In contrast, minilaparotomy can allow early resumption of PD due to the close suturing of the peritoneum. In our study, PD was resumed within 1 week in all except 1 case, and no leakage was found. One patient had a high BMI $\left(30.4 \mathrm{~kg} / \mathrm{m}^{2}\right)$ and diabetes mellitus, so the period of PD interruption was set at 2 weeks. Physiological adverse effects due to $\mathrm{CO}_{2}$ pneumoperitoneum are also disadvantages for laparoscopic surgery [19]. Leung et al. performed laparoscopic salvages of the obstructed catheter and reported that the operation time was 45 to $75 \mathrm{~min}$ [20]. In contrast, our operation time was long. We suspected that omentectomy and preservation of fimbriae of the fallopian tube were responsible for prolonged surgery time. With regard to the hospital stay in laparoscopic salvages, 
Salgaonkar et al. reported that median post-operative hospital stay was 2 days (range 2-5 days) [21]. In contrast, we considered that the hospital stay was long in our patients because PD was initiated after releasing the obstruction.

In conclusion, minilaparotomy for catheter malfunction by nephrologists can be useful for treating catheter malfunction. However, assistance from a surgeon is essential for patients in whom the obstructed catheter cannot be easily removed.

\section{Acknowledgements}

We wish to thank Dr. Minoru Kubota (Ouji Hospital) for advice on surgical techniques through the Aska Peritoneal Dialysis Educational Society

\section{Authors' contributions}

TS, SK, KK, and NK were mainly undertaken this surgical techniques. KK, SY, HS were supported the surgeries and collected the data from medical records. YS contributed greatly to writing the manuscript. All authors read and approved the final manuscript.

\section{Funding}

Not applicable

\section{Availability of data and materials}

The datasets used and analyzed during the current study are available from the corresponding author on reasonable request.

\section{Ethics approval and consent to participate}

The study protocol was approved by the Ethics Committee of St. Marianna University School of Medicine (approval no. 4302).

\section{Consent for publication}

Informed consent was not necessarily due to the retrospective nature of the study. Thus, the need for individual written informed consent was waived. However, a declaration of data use was published on the website. The study information was published on the internet since patients could use the official department website to opt out of the study if they did not want their data used for research purposes.

\section{Competing interests}

The authors declare that they have no competing interests.

\section{Author details}

'Division of Nephrology and Hypertension, Department of Internal Medicine, St. Marianna University School of Medicine, Kawasaki, Japan. ${ }^{2}$ Division of Nephrology and Hypertension, Kawasaki Municipal Tama Hospital, Kawasaki, Japan

Received: 29 December 2019 Accepted: 26 February 2020

Published online: 16 March 2020

\section{References}

1. Robison RJ, Leapman SB, Wetherington GM, Hamburger RJ, Fineberg NS, Filo RS. Surgical considerations of continuous ambulatory peritoneal dialysis. Surgery. 1984;96:723-30.

2. Owens LV, Brader AH. Laparoscopic salvage of Tenckhoff catheters. Surg Endosc. 1995;9:517-8.

3. Kimmelstiel FM, Miller RE, Molinelli BM, Lorch JA. Laparoscopic management of peritoneal dialysis catheters. Surg Gynecol Obstet. 1993;176:565-70.

4. Mutter D, Marichal JF, Heibel F, Marescaux J, Hannedouche T. Laparoscopy: an alternative to surgery in patients treated with continuous ambulatory peritoneal dialysis. Nephron. 1994;68:334-7.

5. Bruhat MA, Chapron C, Mage G, Pouly JL, Canis M, Wattiez A, Glowaczower $\mathrm{E}$. The benefits and risks of laparoscopic surgery. (in French) Rev Fr Gynecol Obstet 1993; 88:84-8.

6. Kim SH, Lee DH, Choi HJ, Seo HJ, Jang YS, Kim DH, et al. Minilaparotomy with manual correction for malfunctioning peritoneal dialysis catheters. Perit Dial Int. 2008;28:550-4.
7. Li JR, Cheng CH, Chiu KY, Cheng CL, Yang CR, Ho HC, et al. Minilaparotomy salvage of malfunctioning catheters in peritoneal dialysis. Perit Dial Int. 2013;33:46-50.

8. Ikeda M, Terawaki H, Kanda E, Furuya M, Tanno Y, Nakao M, et al. Interventional nephrology: current status and clinical impact in Japan. Clin Exp Nephrol. 2018;22:437-47.

9. Moncrief JW, Popovich RP, Dasgupta M, Costerton JW, Simmons E, Moncrief B. Reduction in peritonitis incidence in continuous ambulatory peritoneal dialysis with a new catheter and implantation technique. Perit Dial Int. 1993; 13(Suppl 2):S329-31.

10. Hu J, Liu Z, Liu J, Zhang H. Reducing the occurrence rate of catheter dysfunction in peritoneal dialysis: a single-center experience about CQI. Ren Fail. 2018;40:628-33.

11. Brown PA, McCormick BB, Knoll G, Su Y, Doucette S, Fergusson D, Lavoie S. Complications and catheter survival with prolonged embedding of peritoneal dialysis catheters. Nephrol Dial Transplant. 2008;23:2299-303.

12. Crabtree JH, Burchette RJ. Peritoneal dialysis catheter embedment: surgical considerations, expectations, and complications. Am J Surg. 2013;206:46471.

13. Sinha S, Fok M, Davenport A, Banga N, Lindsey B, Fernando B, et al. Use of the embedded peritoneal dialysis catheter. Ann R Coll Surg Engl. 2018;100: 534-44.

14. Chatterton B. Communication between a continuous ambulatory peritoneal dialysis cannula and right fallopian tube demonstrated radiographically. $\mathrm{Br}$ J Radiol. 1984;57:924-6.

15. Harrison NA, Howell GP, Rainford DJ. Fallopian tube capture of a peritoneal dialysis catheter. Nephron. 1988;50:258.

16. Crabtree JH, Fishman A. Laparoscopic omentectomy for peritoneal dialysis catheter flow obstruction: a case report and review of the literature. Surg Laparosc Endosc Percutan Tech. 1999 Jun;9(3):228-33.

17. Crabtree $\mathrm{JH}$, Fishman A. Selective performance of prophylactic omentopexy during laparoscopic implantation of peritoneal dialysis catheters. Surg Laparosc Endosc Percutan Tech. 2003:13:180-4.

18. Bae IE, Chung WK, Choi ST, Kang J. Laparoscopic internal fixation is a viable alternative option for continuous ambulatory peritoneal dialysis catheter insertion. J Korean Surg Soc. 2012;83:381-7.

19. Ogünç G. Malfunctioning peritoneal dialysis catheter and accompanying surgical pathology repaired by laparoscopic surgery. Perit Dial Int. 2002;22: 454-62.

20. Leung LC, Yiu MK, Man CW, Chan WH, Lee KW, Lau KW. Laparoscopic management of Tenchkoff catheters in continuous ambulatory peritoneal dialysis. A one-port technique. Surg Endosc. 1998;12:891-3.

21. Salgaonkar HP, Behera RR, Sharma PC, Katara A, Bhandarkar DS. Minimally invasive surgery for salvage of malfunctioning peritoneal dialysis catheters. J Minim Access Surg. 2019;15:19-24.

\section{Publisher's Note}

Springer Nature remains neutral with regard to jurisdictional claims in published maps and institutional affiliations.
Ready to submit your research? Choose BMC and benefit from:

- fast, convenient online submission

- thorough peer review by experienced researchers in your field

- rapid publication on acceptance

- support for research data, including large and complex data types

- gold Open Access which fosters wider collaboration and increased citations

- maximum visibility for your research: over $100 \mathrm{M}$ website views per year

At BMC, research is always in progress.

Learn more biomedcentral.com/submissions 